\title{
Formulation and Evaluation of Mouth Dissolving Tablets of Tramadol Hydrochloride
}

\author{
Raja Sridhar Rao.Ponugoti ${ }^{1 *}$ and Chandrasekara Rao Gonugunta ${ }^{2}$ \\ ${ }^{1}$ Department of Pharmaceutics, S.R. College of Pharmacy, Warangal, Andhra Pradesh, ${ }^{2}$ Department of Pharmaceutics, \\ Yalamarty College of Pharmacy, Anandapuram, Visakhapatnam, Andhra Pradesh, India
}

*For correspondence: Email: p.rajasridhar@gmail.com; Tel: +91-9849079102

\begin{abstract}
Purpose: To prepare, and evaluate in vitro and in vivo tramadol hydrochloride mouth dissolving tablets (MDT).

Methods: Tramadol HCI MDT were prepared by direct compression using Pharmaburst as coprocessed excipient and compared with a reference product (Rybix ODT, $50 \mathrm{mg}$ ). Physicochemical parameters including hardness, friability, weight variation, disintegration time and dissolution studies were determined for all the formulations. In-vivo studies were performed for the optimized formulation (F13), using as reference, a commercial product (Trambax IR, $50 \mathrm{mg}$ ), by a two-way crossover design under fasting conditions on eight healthy adult human subjects. Drug-plasma concentrations obtained from the bioequivalence study for test and reference products were analyzed in each subject by high performance liquid chromatography (HPLC), and basic pharmacokinetic parameters, including $C_{\max }$, $T_{\max }, A \cup C_{0-t,}, A \cup C_{0-\infty}, t_{1 / 2}$ and $\lambda_{z}$, were calculated.
\end{abstract}

Results: The tablet formulation prepared with Pharmaburst (F13) showed good flow properties, low disintegration time (15 s) and improved drug release (99\% at $30 \mathrm{~min}$ ) compared with those of the reference product $(88 \%$ at $30 \mathrm{~min}$ ) and passed 6 months accelerated stability test. Bioequivalence of the test product with that of the reference product under fasting conditions was established by computing $90 \%$ confidence interval for the In-transformed pharmacokinetic parameters of $C_{\text {max }}$, AUC $C_{0-t}$ and $A U C_{0-\infty}$ for tramadol. The $90 \%$ confidence intervals for $C_{\max }$ were 99.70 - 114.31, for $A U C_{0-t} 97.31$ 108.87 and for $A \cup C_{0-\infty} 97.17$ - 109.75. This confidence interval, in each case, was within bioequivalence criteria limit

Conclusion: A suitable preparation of tramadol $\mathrm{HCl} M D T$ that is bioequivalent with a reference commercial product under fasting condition can be obtained when Pharmaburst is used as a disintegrant.

Keywords: Bioequivalence, dissolution, Mouth dissolving tablets, Pharmaburst, Tramadol hydrochloride, Disintegration time

Tropical Journal of Pharmaceutical Research is indexed by Science Citation Index (SciSearch), Scopus, International Pharmaceutical Abstract, Chemical Abstracts, Embase, Index Copernicus, EBSCO, African Index Medicus, JournalSeek, Journal Citation Reports/Science Edition, Directory of Open Access Journals (DOAJ), African Journal Online, Bioline International, Open-J-Gate and Pharmacy Abstracts

\section{INTRODUCTION}

The oral route is the most preferred route for administration of therapeutic agents because of ease of administration, accurate dose, self medication and patient compliance. In this regard, tablets and capsules are most preferred dosage forms for oral route. But these dosage forms are difficult to administer to children and geriatrics. Hence, MDT are favoured for its ease of administration and improvement in therapeutic efficacy of dosage form [1-3]. 
Mouth dissolving tablets (MDT) disintegrate and/or dissolve in the mouth (in saliva) within a few seconds without any need to administer it with liquid. They are also called fast dissolving, oro-dispersible, orally disintegrating and fast melting tablets. MDT combines the advantages of both conventional and liquid formulations $[4,5]$.

Tramadol hydrochloride is used to treat moderate to severe pain and it comes under the category of centrally acting analgesics. In India, the drug is available as a conventional tablet, so there is need to develop the mouth dissolving tablets to allow the administration of dosage form with out need of water which is particularly important for pediatrics and geriatrics.

Tramadol hydrochloride Oro dispersible tablets are currently available in USA and Europe and there is no marketed product in India. Therefore, the present work focused on mouth dissolving tablets due to the increasing proportion of the aged in the population and also because of the need to develop appropriate dosage form for the elderly.

\section{EXPERIMENTAL}

\section{Materials}

Tramadol hydrochloride was received as a gift from Jubilant life sciences, Noida and other excipients used in this work was obtained as gifts from BASF, India.

\section{Preparation of mouth dissolving tablets}

Initially, four batches of tramadol $\mathrm{HCl}$ mouth dissolving tablets were formulated by direct compression method and four additional batches were formulated by wet granulation method with the same composition as that of the reference product (Rybix ODT, Shionogi Inc, USA).

Tramadol hydrochloride, mannitol, crospovidone, copovidone, ethyl cellulose and pharmaburst were individually sifted through $420 \mu \mathrm{m}$ aperture sieve size and neotame, tutti frutti flavor, silicon dioxide, colloidal anhydrous silica and magnesium stearate was sifted through $250 \mu \mathrm{m}$ aperture sieve size and collected separately in a polyethylene bag.

Tramadol hydrochloride, mannitol, crospovidone, copovidone, and ethyl cellulose were placed in a (Bectochem Pvt Ltd) and mixed thoroughly for 10 min; sifted silicon dioxide and magnesium stearate were added to the blend and mixed for $5 \mathrm{~min}$. The final blend was compressed into tablets by using a rotary compression machine (KMP-D-8, KAMBERT).

Wet granulation method was used with water as granulating fluid. Initially, the active ingredient and mannitol were dry-mixed and added to the binder solution (water and crospovidone) to obtain a wet mass. Then wet mass was sieved and the produced granules were dried and blended with crospovidone and ethylene cellulose in blender for $10 \mathrm{~min}$. The sifted silicon dioxide and magnesium stearate were added and mixed for 5 min.in the blender. The lubricated blend was compressed into tablets by using rotary compression machine. The composition of the formulations is given in Table 1.

Furthermore, three more batches were prepared by direct compression method with pharmaburst as a co-processed excipient system, colloidal anhydrous silica as glidant and magnesium stearate as lubricant in different concentrations. Initially added sifted Tramadol hydrochloride and pharmaburst into the blender and blended for 10 minutes and then added sifted colloidal anhydrous silica and magnesium stearate to blender and lubricated for 5 minutes and compressed into tablets. Next two more batches were formulated as that of F11 with different concentrations of flavor and sweetener to optimize the organoleptic characteristics. For these two batches the process is same as that of above process; flavor and sweetener was included along with tramadol hydrochloride and Pharmaburst at initial blending step. The composition is given in Table 2 .

Table 1: Composition of tramadol mouth dissolving tablets (MDT)

\begin{tabular}{|c|c|c|c|c|c|c|c|c|}
\hline \multirow[b]{2}{*}{ Ingredient } & \multicolumn{8}{|c|}{ Content (mg/tablet) } \\
\hline & F1 & F2 & F3 & F4 & F5 & F6 & F7 & F8 \\
\hline Tramadol $\mathrm{HCl}$ & 50 & 50 & 50 & 50 & 50 & 50 & 50 & 50 \\
\hline Mannitol & 88.75 & 84.25 & 81.25 & 78.25 & 88.75 & 84.25 & 81.25 & 78.25 \\
\hline Crospovidone & 3.0 & 4.5 & 6.0 & 7.5 & 3.0 & 4.5 & 6.0 & 7.5 \\
\hline Copovidone & 3.0 & 3.75 & 3.75 & 3.75 & 3.0 & 3.75 & 3.75 & 3.75 \\
\hline Water & --- & --- & --- & --- & q.s. & q.s. & q.s. & q.s. \\
\hline Ethyl cellulose & 1.5 & 1.5 & 1.5 & 1.5 & 1.5 & 1.5 & 1.5 & 1.5 \\
\hline Silicon dioxide & 0.75 & 1.5 & 1.5 & 1.5 & 0.75 & 1.5 & 1.5 & 1.5 \\
\hline Magnesium stearate & 3.0 & 4.5 & 6.0 & 7.5 & 3.0 & 4.5 & 6.0 & 7.5 \\
\hline
\end{tabular}


Table 2: Composition details of F9-F13 by direct compression method

\begin{tabular}{lccccc}
\hline \multirow{2}{*}{ Composition } & \multicolumn{5}{c}{ Unit formula (mg/tablet) } \\
\cline { 2 - 6 } & F9 & F10 & F11 & F12 & F13 \\
\hline Tramadol Hydrochloride & 50 & 50 & 50 & 50 & 50 \\
Pharmaburst & 97 & 95.5 & 94 & 92.35 & 91.45 \\
Neotame & --- & --- & --- & 1.5 & 2.25 \\
Tutti frutti flavor & --- & -- & 1.5 & 1.5 & 0.3 \\
Colloidal anhydrous silica & --- & ---5 & 4.5 & 4.5 \\
Magnesium stearate & 3.0 & 4.5 & 4.5 & $\mathbf{1 5 0 . 0}$ & $\mathbf{1 5 0 . 0}$ \\
Total tablet weight & $\mathbf{1 5 0 . 0}$ & $\mathbf{1 5 0 . 0}$ & $\mathbf{1 5 0 . 0}$ & & \\
\hline
\end{tabular}

\section{Evaluation of Blend}

The blend parameters like bulk density, tapped density and compressibility index was performed for all batches according to methods described previously by some authors [6].

\section{Physicochemical characterization compressed tablets}

The physical parameters like hardness, friability, weight variation and disintegration time was performed for all batches of the tablets [7-8]. Other tests including assay, dispersion time and water absorption ratio were performed on the optimized formulation (F13) to evaluate dispersion time and water absorption capacity of the MDTs $[9,10]$.

\section{In-vitro drug release studies}

The study was conducted with six tablets for each formulation using USP type I dissolution apparatus and $900 \mathrm{ml}$ of $0.1 \mathrm{~N} \mathrm{HCl}$ as dissolution medium at a basket rotating speed of $75 \mathrm{rpm}$. Aliquots of $5 \mathrm{ml}$ were withdrawn at selected time intervals through auto sampler and filtered through $0.45 \mu$ filter and the same volume of dissolution medium was used to replenish dissolution medium in order to maintain sink conditions. The absorbance of aliquots was measured at $215 \mathrm{~nm}$ using a UVspectrophotometer after appropriate dilutions. Comparative in-vitro dissolution study was conducted for optimized test formulation with reference product (Trambax, $50 \mathrm{mg}$ immediate release tablet, Ranbaxy Pharmaceuticals, India).

\section{Flavor and sweetener optimization}

The batches F12 and F13 were formulated with tutti frutti as flavor and neotame as taste masking agent in different concentrations. Formulations were given to five human healthy adult volunteers and evaluated the taste and flavor [11].

\section{Assay of drug}

Drug content was measured for optimized formulation F13 by HPLC method at $271 \mathrm{~nm}$ using $\mathrm{C}_{18} 250 \mathrm{~mm} \times 4.6 \mathrm{~mm}, 5 \mu \mathrm{m}$ column with an injection volume of $20 \mu \mathrm{l}$ at a flow rate of 1.0 $\mathrm{ml} / \mathrm{min}$ [12].

\section{Stability studies}

As per $\mathrm{ICH}$ guidelines, accelerated stability studies were conducted for optimized formulation F13 for a period of six months. The tablets were withdrawn from stability chamber after $1^{\text {st }}, 2^{\text {nd }}$, $3^{\text {rd }}, 6^{\text {th }}$ months and analyzed for friability, assay, dissolution, disintegration time and dispersion time [13].

\section{In-vivo bioequivalence studies}

Before commencing the study, the protocol (no. 355-03/SRPH/WGL/IHEC/2012) of the study was approved by the institutional ethical committee. The study was conducted as per the $\mathrm{ICH}$ harmonized tripartite guideline, namely, Guidelines for Good Clinical Practice (E6) [14]. The study was conducted on eight healthy adult male human subjects at SR College of Pharmacy, affiliated to Kakatiya University, Warangal, India. The subjects were selected based on a defined inclusion/exclusion criteria, medical history and physical examination.

\section{Inclusion and exclusion criteria}

Subjects enrolled in the study had a body mass index between 18.5 to $30.0 \mathrm{~kg} / \mathrm{m}^{2}$, body weight not $<50 \mathrm{~kg}$. Other vital parameters were blood pressure (BP) within the range of $100-139$ $\mathrm{mmHg}$ systolic and $60-89 \mathrm{mmHg}$ diastolic; pulse rate $60-100 / \mathrm{min}$ and oral temperature between $36.55^{\circ} \mathrm{C}-37.2^{\circ} \mathrm{C}$.

Subjects excluded from the study include those having a history of smoking, drinking, tuberculosis, diabetes mellitus, renal, cardiac, hepatic, metabolic, neurological and hematological systems. 


\section{Study design}

Open label, single dose, randomized, two treatment, two period, two sequence, two-way crossover study under fasting conditions with a washout period of seven days.

\section{Collection of blood samples}

Twenty blood samples were collected from each subject at various intervals ranging from 0.0 (predosing) to $24 \mathrm{~h}$. After dosing, the collected blood samples were transferred to heparin sodium tubes, centrifuged, plasma was separated and stored in a deep freezer pending analysis.

\section{Analysis of tramadol hydrochloride}

The plasma samples were analyzed by validated HPLC method using empowers chromatography software. Chromatographic separation was done by using Chromolith TM Performance RP-18e $50 \mathrm{~mm} \times 4.6 \mathrm{~mm}$ column protected by a Chromolith TM Guard Cartridge RP-18e $5 \mathrm{~mm} \times 4.6 \mathrm{~mm}$. And phosphoric acid was used for adjustment of $\mathrm{pH}$ to 2.5 for methanol: water mixture $(13: 87 \mathrm{v} / \mathrm{v})$ [15].

\section{Pharmacokinetic and statistical analysis}

For each subject after every time interval the Tramadol hydrochloride plasma concentrations and time data were analyzed by using noncompartmental model of WinNonlin software version 5.3 and calculated basic pharmacokinetic parameters like $\mathrm{C}_{\max }, \mathrm{T}_{\max }, \mathrm{AUC}_{0-\mathrm{t}}, \mathrm{AUC}_{0-\infty}$ and also calculated formulation means of tramadol hydrochloride and $90 \%$ confidence interval. The statistical significant differences between groups were defined as $p<0.05$.

\section{RESULTS}

\section{Physical Characterization of Powder blend before compression}

The various physical characterization of powder blend like bulk density, tapped density and compressibility index were performed and the results of the same were given in the Table 3 .

\section{Evaluation of Physical parameters of tablets}

The various physical parameters of tablets like hardness, friability, weight variation and disintegration time were performed and the results of the same were given in the Table 4

The other parameters for optimized formulation (F13) like assay, water absorption ratio and dispersion time were performed and the results of the same were given in the Table 5.

Table 3: Physical characteristics of powder blend

\begin{tabular}{llll} 
Batch & Parameter & \\
\cline { 2 - 4 } & $\begin{array}{l}\text { Bulk } \\
\text { density } \\
\left(\mathbf{g} / \mathbf{c m}^{-3}\right)\end{array}$ & $\begin{array}{l}\text { Tapped } \\
\text { density } \\
\left(\mathbf{g} / \mathbf{c m}^{-3}\right)\end{array}$ & $\begin{array}{l}\text { Carr's } \\
\text { index } \\
(\%)\end{array}$ \\
\hline TM 01 & 0.66 & 1.00 & 34 \\
TM 02 & 0.68 & 1.02 & 33 \\
TM 03 & 0.66 & 0.90 & 27 \\
TM 04 & 0.66 & 0.89 & 26 \\
TM 05 & 0.71 & 0.95 & 25 \\
TM 06 & 0.72 & 0.94 & 23 \\
TM 07 & 0.74 & 0.93 & 20 \\
TM 08 & 0.74 & 0.92 & 20 \\
TM 09 & 0.72 & 0.88 & 18 \\
TM 10 & 0.72 & 0.86 & 17 \\
TM 11 & 0.70 & 0.80 & 13 \\
TM 12 & 0.70 & 0.78 & 10 \\
TM 13 & 0.70 & 0.78 & 10 \\
\hline
\end{tabular}

Table 5: Parameters for optimized formulation (F13)

\begin{tabular}{lc}
\hline Parameter & \multicolumn{1}{c}{ Value } \\
\hline Drug content (\%) & $99.7 \pm 0.7$ \\
Water absorption ratio (\%) & $103.2 \pm 0.6$ \\
Dispersion yime (s) & $10.0 \pm 0.2$ \\
\hline
\end{tabular}

\section{In-vitro drug release}

The in-vitro drug release studies were performed for all batches of tablets but initial batches i.e. F1-F8 did not met the targeted release profile. But next batches i.e. F9-F11 were found to be satisfactory and drug release data was shown in Figure 1

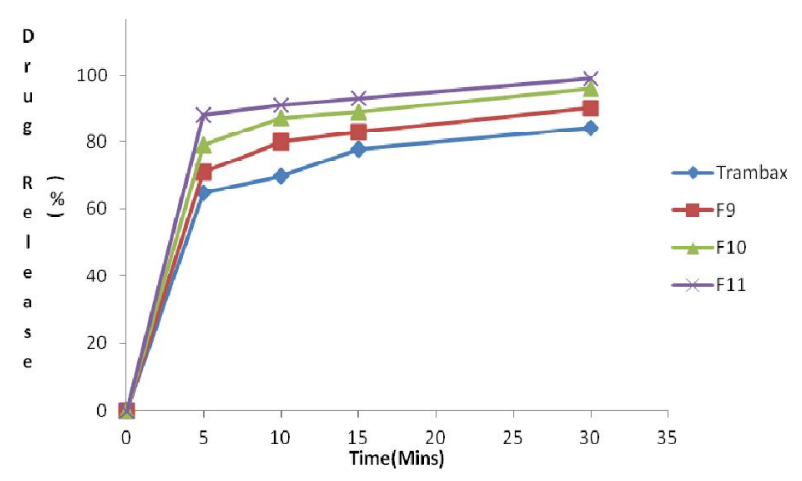

Figure 1: Comparative dissolution profiles of tramadol MDTs

\section{Stability studies}

The accelerated stability study was conducted for optimized formulation F13 for a period of 6 months and the results revealed that there was no noticeable change observed in dissolution, assay, friability, disintegration time and 
Table 4: Some physical parameters of tablets (mean \pm SD)

\begin{tabular}{lcccc}
\hline Batch & $\begin{array}{c}\text { Hardness } \\
\left(\mathbf{k g} / \mathbf{c m}^{\mathbf{2}}\right)\end{array}$ & $\begin{array}{c}\text { Friability } \\
(\boldsymbol{\%})\end{array}$ & Mean weight $(\mathbf{m g})$ & $\begin{array}{c}\text { Disintegration } \\
\text { time } \mathbf{( s )}\end{array}$ \\
\hline TM 01 & $4.59 \pm 0.7$ & $0.11 \pm 0.03$ & $148.2 \pm 1.15$ & $104 \pm 1.85$ \\
TM 02 & $4.49 \pm 0.9$ & $0.12 \pm 0.02$ & $147.9 \pm 1.64$ & $95 \pm 2.12$ \\
TM 03 & $4.18 \pm 0.6$ & $0.11 \pm 0.04$ & $150.5 \pm 1.86$ & $84 \pm 2.15$ \\
TM 04 & $4.28 \pm 1.4$ & $0.13 \pm 0.06$ & $149.1 \pm 1.22$ & $78 \pm 2.52$ \\
TM 05 & $4.79 \pm 0.5$ & $0.10 \pm 0.05$ & $148.6 \pm 1.26$ & $98 \pm 1.85$ \\
TM 06 & $4.28 \pm 1.1$ & $0.11 \pm 0.02$ & $146.2 \pm 2.24$ & $87 \pm 1.26$ \\
TM 07 & $4.08 \pm 0.8$ & $0.12 \pm 0.05$ & $148.5 \pm 1.95$ & $75 \pm 1.65$ \\
TM 08 & $4.18 \pm 0.7$ & $0.16 \pm 0.03$ & $148.2 \pm 2.16$ & $60 \pm 1.18$ \\
TM 09 & $4.08 \pm 0.8$ & $0.10 \pm 0.08$ & $147.3 \pm 2.12$ & $45 \pm 1.24$ \\
TM 10 & $4.38 \pm 0.8$ & $0.13 \pm 0.09$ & $148.2 \pm 1.24$ & $28 \pm 1.02$ \\
TM 11 & $4.18 \pm 0.8$ & $0.12 \pm 0.06$ & $147.9 \pm 1.28$ & $15 \pm 0.68$ \\
TM 12 & $4.28 \pm 0.9$ & $0.11 \pm 0.06$ & $148.5 \pm 1.08$ & $16 \pm 0.89$ \\
TM 13 & $4.18 \pm 0.8$ & $0.12 \pm 0.08$ & $148.6 \pm 1.15$ & $15 \pm 0.62$ \\
\hline
\end{tabular}

Table 6: Stability data for optimized formulation (mean \pm SD)

\begin{tabular}{llllll}
\hline Parameter & \multicolumn{5}{c}{ Time (month) } \\
\cline { 2 - 6 } & Initial & $\mathbf{1}^{\text {st }}$ & $\mathbf{2}^{\text {nd }}$ & $\mathbf{3}^{\text {rd }}$ & $\mathbf{6}^{\text {th }}$ \\
\hline Dissolution & 85 & 84 & 85 & 83 & 85 \\
5 min & 90 & 89 & 91 & 89 & 89 \\
10 min & 95 & 95 & 96 & 94 & 96 \\
15 min & 99 & 99 & 99 & 98 & 99 \\
30 min & 99.7 & 99.7 & 99.6 & 99.8 & 99.8 \\
Drug content (\%) & $0.12 \pm 0.08$ & $0.10 \pm 0.04$ & $0.18 \pm 0.06$ & $0.15 \pm 0.05$ & $0.19 \pm 0.08$ \\
Friability (\%) & $15 \pm 0.62$ & $13 \pm 0.09$ & $16 \pm 0.95$ & $17 \pm 0.49$ & $14 \pm 0.14$ \\
Disintegration time (min) & $10 \pm 0.24$ & $11.8 \pm 0.33$ & $11.5 \pm 0.31$ & $11 \pm 0.15$ & $12.1 \pm 0.18$ \\
Dispersion time (min) & & & & & \\
\hline
\end{tabular}

Table 7: Descriptive statistics of test MDT and reference products

\begin{tabular}{llc}
\hline & \multicolumn{1}{c}{$\begin{array}{c}\text { Mean } \pm \text { SD } \\
\text { (Un - transformed) }\end{array}$} \\
\cline { 2 - 3 } Parameter & \multicolumn{1}{c}{ Test MDT } & Reference \\
\hline $\mathrm{C}_{\max }(\mathrm{ng} / \mathrm{ml})$ & $171.466 \pm 30.254$ & $162.665 \pm 25.165$ \\
UUC $_{0-\mathrm{t}}(\mathrm{mg} . \mathrm{h} / \mathrm{ml})$ & $1488.098 \pm 242.101$ & $1450.378 \pm 257.422$ \\
AUC $0-\infty(\mathrm{ng} \cdot \mathrm{h} / \mathrm{ml})$ & $1629.404 \pm 296.234$ & $1581.535 \pm 307.192$ \\
AUC_\%Extrap_obs $(\%)$ & $8.287 \pm 3.429$ & $7.925 \pm 3.373$ \\
$\operatorname{Tmax}(\mathrm{h})$ & $1.844 \pm 0.516$ & $2.219 \pm 0.619$ \\
$\mathrm{t} 1 / 2(\mathrm{~h})$ & $6.653 \pm 1.272$ & $6.385 \pm 1.145$ \\
$\lambda_{z}(\mathrm{~h})$ & $0.107 \pm 0.018$ & $0.111 \pm 0.018$ \\
\hline
\end{tabular}

Table 8: 90\% confidence intervals for tramadol hydrochloride

\begin{tabular}{lcccc}
\hline & Ratio & \multicolumn{2}{c}{$\mathbf{9 0 \%}$ Confidence interval } & \\
\cline { 3 - 4 } Parameter & {$[$ A/B ]\% } & Lower & Upper & Power \\
\hline $\mathrm{C}_{\max }(\mathrm{ng} / \mathrm{ml})$ & 106.76 & 99.70 & 114.31 & 100.00 \\
$\mathrm{AUC}_{0-\mathrm{t}}(\mathrm{ng} \cdot \mathrm{h} / \mathrm{ml})$ & 102.93 & 97.31 & 108.87 & 100.00 \\
$\mathrm{AUC}_{0-\infty}(\mathrm{ng} \cdot \mathrm{h} / \mathrm{ml})$ & 103.27 & 97.17 & 109.75 & 100.00 \\
\hline${ }^{*}$ Calculated for in-transformed data & & &
\end{tabular}

${ }^{*}$ Calculated for in-transformed data

\section{In-vivo bioequivalence}

In-vivo studies were performed and results of descriptive statistics of test and reference product was shown in Table 7 and $90 \%$ confidence interval of Tramadol hydrochloride was shown in Table 8, and mean plasma concentration vs. time profile of tramadol hydrochloride was shown in Figure 2.

\section{DISCUSSION}

All batches of blend (F1-F13) were evaluated for blend parameters and confirmed that lubricated blend was very much useful for compression and the results were found to be satisfactory. Also all batches of tablets were evaluated for physical parameters like hardness, friability, average weight and disintegration time. The results of all 
parameters were found to be within the acceptable Pharmacopoeial limit. Other parameters like assay, dispersion time and water absorption ratio were performed for optimized formulation (F13) and results were found to be satisfactory.

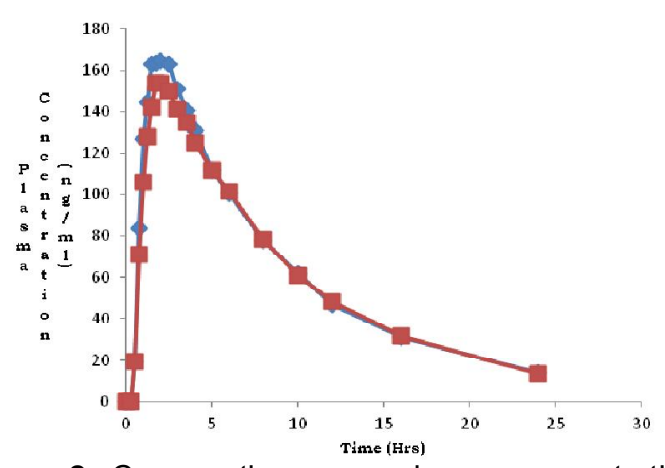

Figure 2: Comparative mean plasma concentrations vs. time profiles. Note: $\boldsymbol{\|}=$ reference; $\downarrow$ = test product

In-vitro drug release studies for initial batches i.e. F1-F4 were showed very slow rate of drug release and dissimilar with reference product drug release at all time intervals. No improvement of drug release was observed for further batches i.e. F5-F8 even though the method of preparation of tablets was changed. The preceded batches of tablets were showed deviations in drug release, so next batches were formulated by changing the composition of the drug product with pharmaburst. The batch F9 showed better drug release than the preceded batches and met the reference product's drug release profile at all time intervals but did not met the targeted release profile $(80 \%$ of drug should release with in 5 minutes). The F10 batch showed improved drug release than F9 batch and meeting the drug release of reference product at all time intervals but did not met the targeted release profile. F11 batch showed to improve the drug release than the reference product and also met the targeted drug release as per the dissolution concern and confirmed that F11 batch was the optimized formulation. Next batches were formulated with same composition as that of F11 to optimize the organoleptic characteristics. The formulation prepared with $1.5 \%$ of neotame and $0.2 \%$ of tutti frutti flavor i.e. F13 batch was showed very good taste and flavor than other formulations and was confirmed as optimized formulation in concern of disintegration time, dispersion time, dissolution and organoleptics.

Six months accelerated stability study was conducted for optimized formulation F13 and observed that all parameters were found to be within the limit and the drug was stable for a period of 6 months at accelerated condition with out any noticeable change and confirmed that F13 batch was the optimized formulation. Then in-vivo studies were conducted for optimized formulation F13 with reference product under fasting condition. In each subject, drug and plasma concentrations were analyzed by HPLC and the pharmacokinetic parameters like $\mathrm{C}_{\max }$, $T_{\text {max }}, A \cup C_{0-t}$ and $A U C_{0-\infty}$ and means of test and reference product were observed. The descriptive statistics and $90 \%$ confidence interval of Tramadol hydrochloride was calculated and found that test formulation is bioequivalent with reference product.

\section{CONCLUSION}

Tablets prepared with Pharmaburst as coprocessed excipient is the most suitable disintegrant for the preparation of mouth dissolving tablets. The optimized test formulation showed superior drug release to reference product and also demonstrated good stability over a period of 6 months. It was bioequivalent with the reference product used in the study.

\section{REFERENCES}

1. Takao Mizumoto, Yoshinori Masuda, Takeshi Yamamoto, Estuo Yonemochi, Katsuhide Terada. Formulation design of a novel fast-disintegrating tablet. Int. J. Pharm. 2005; 306: 83-90.

2. Srikonda Venkateswara Sastry, Janaki Ram Nyshadham, Joseph A. Fix. Recent technological advances in oral drug delivery - a review. Pharm. Sci. Tech 2000; 3: 138-145.

3. Gohel, MC, PD Jogani. A review of co-processed directly compressible excipients. J. Pharm Sci 2005; 8: 76-93.

4. Bi Y, Sunada H, Yonezawa Y, Dayo K, Otsuka A, lida K. Preparation and evaluation of a compressed tablet rapidly disintegrating in oral cavity. Chem. Pharm. Bull 1996; 44: 2121-2127.

5. Fu Y, Yang S, Jeong SH, Kimura S, Park K. Orally fast disintegrating tablets: developments, technologies, taste-masking and clinical studies. Crit. Rev. Ther. Drug 2004; 21: 433-476.

6. EC. Abdullah, D. Geldart. The use of bulk density measurements as flow ability indicators. Powder Technol 1999; 102: 151-165.

7. European pharmacopoeia. "Pharmaceutical technical procedures: Disintegration test, Uniformity of mass, Friability, Resistant to crushing", ed 7, EDQM, Council of Europe, Strasbourg, France, 2011; 253254, 265-267.

8. Sateesh K. VEMULA, Prabhakar R. VEERAREDDY. Fast Disintegrating Tablets of Flurbiprofen: Formulation and Characterization. Lat. Am. J. Pharm 2011; 30: 1135-1141.

9. Hisakadzu Sunada, Yunxia Bi. Preparation, evaluation and optimization of rapidly disintegrating tablets. Powder Technol 2002; 122: 188-198.

10. A. Abdelbary, AH. Elshafeey, G. Zidan. Comparative effects of different cellulosic-based directly compressed orodispersable tablets on oral bioavailability of famotidine. Carbohyd. Polym 2009; 77: 799-806. 
11. Jianchen $\mathrm{Xu}$, Li Li Bovet, Kang Zhao. Taste masking microspheres for orally disintegrating tablets. Int. J. Pharm 2008; 359: 63-69.

12. British Pharmacopoeia. "BP monographs: Tramadol hydrochloride" 2011; Vols I \& II: p 1595.

13. International Conference on Harmonization "Q1E Evaluation of Stability Data" 5600, Fishers Lane, Rockville 2004; 1-21.
14. International Conference on Harmonization "E6 Guideline for Good Clinical Practice" 5600, Fishers lane, Rockville 2006: 1-59.

15. Yalda H. Ardakani, Mohammad-Reza Rouini. Pharmacokinetics of Tramadol and its Three Main Metabolites in Healthy Male and Female Volunteers. Biopharm. Drug Dispos 2007; 28: 526533. 